\title{
“Dallas Buyers Club” o cómo resistirse a la deriva segregativa
}

\author{
Dallas Buyers Club | Jean-Marc Vallée | 2013 \\ Joaquín Carrasco
}

Nueva Escuela Lacaniana-Sede Santiago, Chile

Recibido: 11 de julio 2020; aceptado: 18 de agosto 2020

\begin{abstract}
Resumen
Se aborda la segregación como uno de los fenómenos que se producen tras la irrupción de una pandemia. Con la película Dallas Buyers Club, dirigida por Jean-Marc Vallée (2013), se explora el tema a partir de la expansión del VIH en los EEUU de la década de los '80. ¿Qué podemos decir desde la ética del psicoanálisis sobre estos fenómenos de segregación, los efectos y salidas posibles para un sujeto? Para pensar algunas respuestas posibles se plantea inicialmente una aproximación hacia la ética del psicoanálisis. Posteriormente, se propone una lectura de la película considerando el carácter traumático del virus, las distintas dimensiones que toma la segregación y las soluciones que le permiten al protagonista no quedar ubicado como objeto de desecho. Para finalizar, se plantean algunas reflexiones sobre un posible abordaje de los fenómenos segregativos desde una ética que promueve la singularidad.
\end{abstract}

Palabras clave: cine | pandemia | VIH | segregación | ética | psicoanálisis

Unbearable strangeness

\begin{abstract}
In this article, segregation is addressed as one of the phenomena that occur after a pandemic outbreak. By the film Dallas Buyers Club (2013), directed by Jean-Marc Vallée, this issue is explored from the spread of HIV in the US in the 1980s. What can we say from psychoanalysis ethics about these phenomena of segregation, it's possible effects and outputs for a subject? In order to think about some possible answers, an approach towards psychoanalysis ethics is initially proposed. After that, a reading of the film is proposed considering the traumatic nature of the virus, the different dimensions of segregation and the solutions that allow the protagonist not to be considered as a waste object. Finally, some reflections on a possible approach to segregative phenomena are proposed from an ethic that promotes singularity.
\end{abstract}

Keywords: cinema| pandemic|VIH | segregation| ethics| psycoanalisis

\section{Introducción}

La irrupción y extensión de una pandemia suele producir un efecto de estupor, al menos en un primer momento, dando paso al despliegue de una serie de esfuerzos por intentar agarrar algo que se presenta fuera de los límites del saber. A través de distintas estrategias, más o menos efectivas, los gobiernos intentan controlar eso que parece incontrolable. Los científicos investigan sobre el agente infeccioso y sus características. Cada quien acude a sus recursos para enfrentar esta amenaza que pone sobre la mesa la cuestión de la muerte. El modo en que se responde a este acontecimiento ya sea a nivel gubernamental, social o subjetivo, implica una decisión y con ello se pone en juego la cuestión ética. Por supuesto, esto incluye al psicoanálisis.

Desde su entrada en escena, el virus produce efectos que pueden considerar la dimensión médica pero que la excede por completo, entre los cuales encontramos los fenómenos de segregación, significante que encuentra su raíz etimológica en segregare y que en su origen significa “apartar del rebaño". Un dejar por fuera del conjunto que podemos pensar como efecto de discurso. Pero también, como veremos más adelante, se trata de un rechazo que atañe al goce. Ser parte de un rebaño tiene consecuencias. Ser apartado también.

La cuarentena es quizás la experiencia que hoy se nos vuelve más cercana y cotidiana, del modo en que se limi-

joaquin.carrasco@uc.cl 
ta la circulación de los cuerpos para evitar la propagación de la pandemia, o para permitir que se propague de tal modo que no colapsen los sistemas sanitarios. Una limitación que no demora en comenzar a producir efectos subjetivos y en el lazo social. Esta segregación, a la que podemos suponer un espíritu salubrista, afecta de diversos modos a la población, pero tiene como objetivo limitar la propagación del virus y sus efectos negativos en la salud. Hay otros fenómenos de segregación que por el contrario llevan hacia la ruptura del lazo social, el empobrecimiento y la muerte. Me interesa indagar sobre este tipo de segregación como respuesta ante una pandemia, tomando el caso de la irrupción del VIH en EEUU, considerando la dimensión social y el modo en que un sujeto se ubica frente a la deriva segregativa.

El cine permite aproximarnos a este tema desde diversos puntos de vista. Destaco entre ellas la película biográfica Dallas Buyers Club, dirigida por Jean-Marc Vallée (2013), que da cuenta de la segregación que debe enfrentar un sujeto -Ron Woodroof (Matthew McConaughey)- luego de ser diagnosticado con SIDA en la década de los '80 en EEUU. Muestra un recorrido que va desde el impacto que provoca el diagnóstico, en términos subjetivos y en el lazo social, hacia la búsqueda de soluciones ante esta coyuntura inesperada. Además, permite pensar en las distintas dimensiones en que se pone en juego el rechazo. ¿Qué podemos decir desde la ética del psicoanálisis sobre estos fenómenos de segregación, los efectos y salidas posibles para un sujeto? ¿Se puede evitar -o al menos esquivar- el rechazo que despierta un virus emparentado a la muerte?

\section{Una aproximación a la ética del psicoanálisis}

Desde el psicoanálisis, se enfatiza la distinción entre ética y moral. Tal como sostiene Domenico Cosenza (2012), desde Freud se puede rastrear una operación de deconstrucción de los fundamentos imaginarios de la moral occidental, operación que Lacan profundiza. La moral se propone como un saber universal, respondiendo a un orden categórico donde aparece el superyó como mando mortífero y el sujeto queda en la posición de obedecer dicho mando. La ética, por el contrario, concierne a la experiencia analítica y remite a esos momentos cruciales en que se pone en juego la dimensión del acto y la elección que siempre implica una pérdida para el sujeto.

Para Cosenza (2012), la ética del psicoanálisis implica empujar al sujeto a querer saber algo de lo que está en el corazón de su posición, alrededor de lo más íntimo de su ser. Se trata de un encuentro que va más allá de la dimensión terapéutica del psicoanálisis. Además, retoma el Seminario 11 de Lacan para enfatizar que el inconsciente mismo da cuenta de una ética, y no de una ontología. Eso quiere decir que dependerá del sujeto la existencia del inconsciente. Hay allí también una elección.

Un punto interesante en esta distinción es la cuestión de la responsabilidad del sujeto. Una responsabilidad que no se desprende de las declaraciones o la buena voluntad. Tampoco se trata de un empuje hacia la responsabilidad que pudiera derivar en un mandato superyoico. Ejemplo de ello sería intentar hacer responsable a un sujeto de aquello que lo excede. Se trata más bien de poner en relieve la posición que un sujeto toma ante sus dichos. En ese punto nos orienta una ética de las consecuencias. Es una de las lecturas que podemos hacer ante la indicación: "De nuestra posición de sujeto somos siempre responsables" (Lacan, 1965, p.816). La amenaza de una pandemia provoca diversas consecuencias subjetivas, como también diversas posiciones entre los sujetos afectados. La posición que un sujeto toma ante un virus que viene a conmover su existencia puede ir mutando, tal como muestra el protagonista.

¿Cómo concebimos la ética del psicoanálisis, una ética que privilegia la singularidad, más allá de la experiencia analítica? Entramos en un terreno que contempla lo que ocurre en la ciudad. En esta línea, Éric Laurent (2000) cuestiona la versión del analista que critica lo que ocurre encerrado en su consulta y plantea que

los analistas han de entender que hay una comunidad de intereses entre el discurso analítico y la democracia, ipero entenderlo de verdad! Hay que pasar del analista encerrado en su reserva, crítico, a un analista que participa, un analista sensible a las formas de segregación, un analista capaz de entender cuál fue su función y cuál le corresponde ahora. (p.115)

En una entrevista sobre acción lacaniana, Graciela Brodsky (2003) plantea que

la ética del psicoanálisis supone tomar partido dentro y fuera del consultorio. Tomar partido contra los ideales del amor humano, de la autenticidad y de la no-dependencia; contra la identificación masificadora, contra la soledad posmoderna, contra la dirección de conciencia. (s/p.)

Son algunos ejemplos de cómo se puede pensar una posición orientada por la ética del psicoanálisis en la ciudad. Éric Laurent (2000) también refiere al riesgo que implican los ideales, para plantear que "el decir silencioso del analista consiste en ayudar a que, cada vez que se 
intenta erigir un nuevo ideal, pueda denunciarse que la promoción de nuevos ideales no es la única alternativa" (p.118). La distancia con esos ideales se puede acentuar justamente a partir del contagio de una epidemia como el VIH, tal como podemos ver en Dallas Buyers Club.

\section{El impacto de un virus}

La película comienza con la irrupción de lo inesperado. La vida de Ron Woodroof se ve alterada por la aparición de síntomas como fatiga, tos recurrente y desmayo. Estos síntomas no encajan con su semblante viril tradicional, con el cual se muestra rudo, fuerte, mujeriego y homofóbico. Al no dar lugar a estos malestares, es necesario un accidente laboral para que llegue al hospital. Al despertar, el equipo médico le ha hecho un examen de sangre y le informan que es portador de VIH, con un pronóstico de 30 días de vida.

El médico le pregunta si ha tenido conductas homosexuales, ante lo cual Ron se agita y amenaza con golpearlo. Tiene suspicacia respecto al diagnóstico, no lo ve como algo posible, pero lo que despierta un rechazo radical es la posibilidad de ser ubicado dentro del conjunto de los homosexuales. Un rechazo hacia un modo de obtener goce sexual, que da cuenta de una aversión generalizada propia de mediados de la década de los '80 en EEUU. Como primera respuesta, Ron recurre a su semblante viril para afirmar que nada lo puede matar en 30 días e intenta continuar con su vida como si todo lo ocurrido hubiese sido un error o bien una exageración.

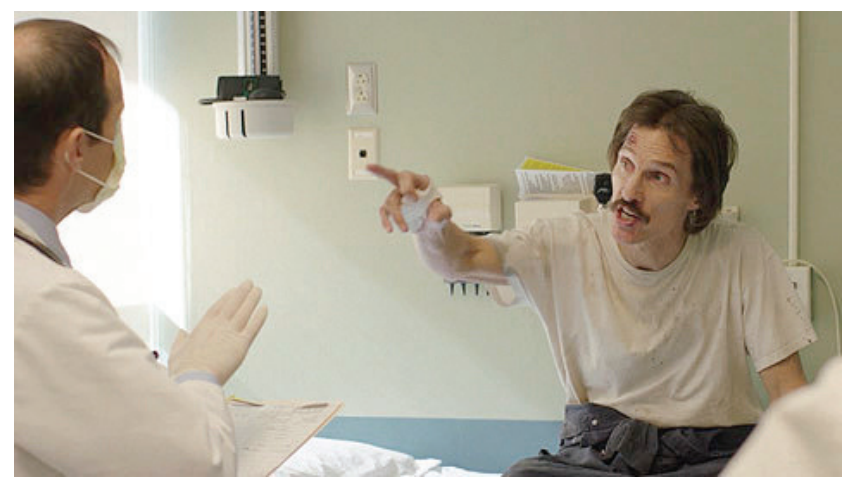

Desechar el diagnóstico es la primera posición que este sujeto toma ante el virus. No obstante, es una posición que no consigue sostener ante la insistencia de los síntomas. En este punto, irrumpe un real que pone en jaque el semblante y el sentido. A partir de este efecto podemos concebir esta experiencia como traumática, en tanto "el trauma está siempre del lado de lo incomprensible, no del gran acontecimiento sino del acontecimiento en tanto que fuera de sentido y eso es lo que nos muestra el parentesco entre el trauma y lo Real" (Brodsky, 2016, p.165). Una primera reflexión ética se desprende de cómo concebimos lo traumático para un sujeto.

Podemos notar la presencia de discursos totalizantes que pretenden definir lo traumático a partir de las características del acontecimiento, y a partir de ello construir escalas que se esfuerzan por medir qué tan traumatizado se encuentra un sujeto. Como consecuencia, se escucha más al instrumento que al sujeto en cuestión. Para el psicoanálisis, por el contrario, lo traumático no se define por las características del hecho en sí mismo, o el impacto que podemos suponer desde nuestra propia subjetividad. Se trata más bien del carácter disruptivo en relación a la capacidad de simbolización: "Un acontecimiento, grande o pequeño, es traumático en la medida en que no se puede simbolizar, es trauma porque no se consigue darle sentido, porque no entra en la cadena de ficciones con la que se teje nuestra realidad cotidiana" (Brodsky, 2016, p.167). Solo sabremos si un acontecimiento es traumático a posteriori, es decir, a partir de las consecuencias que tuvo para un sujeto. Y si hablamos de un sujeto, ello implica estar advertidos de que lo traumático puede ser un acontecimiento que para otro sujeto sea insignificante. El psicoanálisis enfatiza la singularidad, en tanto apunta a "escuchar las secuelas, los efectos de esos encuentros con lo real traumático, y esas secuelas no pueden ser sino singulares, aun cuando el fenómeno sea colectivo" (Brodsky, 2016, p.162).

¿Qué hace un sujeto ante este encuentro con lo real que implica el trauma? En el caso de Ron, el fuera de sentido que provoca la insistencia de los síntomas lo lleva a buscar información sobre el virus. Se entera de las posibles vías de contagio y aparece el recuerdo de un encuentro sexual sin protección con una mujer que se drogaba por medio de inyecciones. Se consigue bordear lo real por medio del sentido que ofrece la ciencia, produciéndose un giro. Se percata de que se está muriendo, cesa el rechazo hacia el diagnóstico y se las arregla para comenzar a recibir medicación.

\section{Dimensiones de la segregación}

La película nos enseña sobre las distintas dimensiones en que se pone en juego la segregación. Una de ellas remite a la relación que el protagonista establece en un 
primer momento con un cuerpo que comienza a presentar síntomas impensados, un cuerpo enfermo que le incomoda. Se trata de un esfuerzo estéril por dejar fuera los síntomas que no dejan de insistir.

También encontramos por parte de Ron un rechazo radical hacia aquello que se le presenta como diferente y con lo cual corre el riesgo de ser asociado. Rechaza profundamente a los homosexuales. Cuando no le queda otra opción que aceptar el diagnóstico, acude a un grupo de apoyo para buscar información, y ante el intento de establecer una conversación por parte de uno de los asistentes, un hombre homosexual, se despierta su aversión. O bien cuando conoce en el hospital a Rayon (Jared Leto), una mujer trans que comparte su diagnóstico. Lo interesante es que este empuje segregativo, vehiculizado por el rechazo hacia lo que escapa a la heterosexualidad, se va transformando en el transcurso de los hechos.

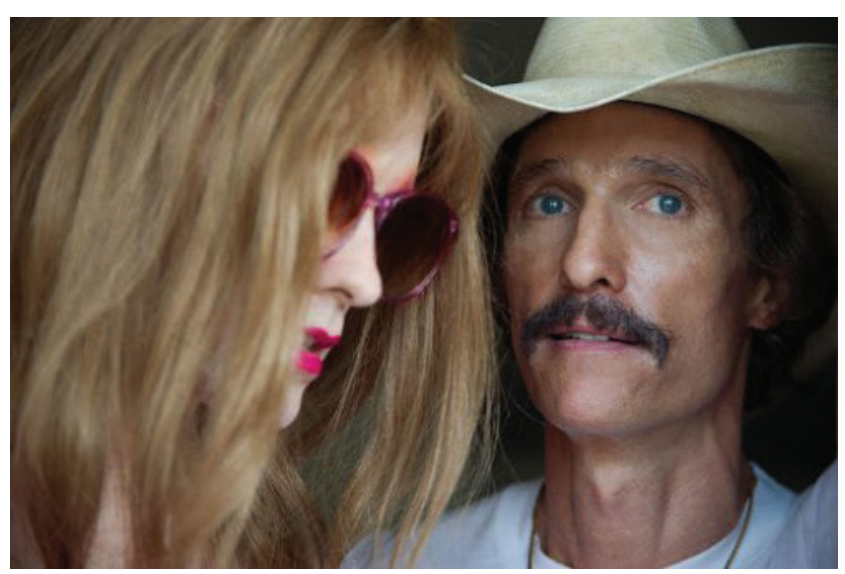

Podemos pensar otra dimensión de la segregación cuando es Ron quien pasa a ser objeto de rechazo. Una escena clave es cuando va al bar y es objeto de burlas homofóbicas por parte de quienes eran sus amigos. Bromas que por supuesto escucha como insultos. Es interesante que la segregación no se debe tanto a su diagnóstico médico, sino por la suposición de que ha tenido relaciones sexuales con hombres. El rechazo es fundamentalmente hacia un modo de gozar. Poco después va a su lugar de trabajo, donde también se encuentra con algunos de sus amigos. El acceso está bloqueado. Entiende que ya no cuenta con un lugar ahí. Como si no fuera suficiente, al volver a su casa se encuentra con las paredes rayadas. "Fagged blood". Los insultos llegan a escribirse en su espacio más íntimo. De un momento a otro, se queda sin amigos, sin trabajo, excluido de espacios que solía habitar y teniendo que lidiar con el rechazo.

Otra dimensión a considerar remite al contexto so- ciocultural de la época. El rechazo hacia homosexuales y portadores de VIH es constante y cotidiano. Para sorpresa de algunos, este rechazo también está presente en las instituciones de salud. Desde el Estado, que en teoría garantiza la igualdad de derechos para sus ciudadanos, se promueven políticas segregativas que atentan contra la vida de una parte de la población. Es lo que muestra la película respecto a las medidas tomadas por la FDA (Food and Drug Administration), como la autorización para la experimentación con un medicamento altamente tóxico (AZT), existiendo otras opciones que tienen menos efectos secundarios y mejores resultados de esperanza de vida. El conflicto entre lo permitido por la legislación y la posibilidad del uso de otros fármacos más efectivos, pero no aprobados, es encarnado por Eve Sacks (Jennifer Garner), la médica tratante. Sabe de la peligrosidad del medicamento aprobado, pero no puede indicar otras opciones. La limitación legal impone un dilema ético.

Una de las críticas ante el manejo inicial frente a la epidemia del VIH-SIDA fue justamente la falta de esfuerzos y políticas necesarias para una reducción significativa en las tasas de contagio y los obstáculos impuestos para acceder a mejores medicamentos. Cabe preguntarse si el abordaje habría sido el mismo si la población afectada en ese tiempo inicial no hubiese sido principalmente sujetos que se ubicaban por fuera de los ideales en torno a la sexualidad. En este contexto es que surgen movimientos de denuncia ante las medidas tomadas por la FDA, que en lo concreto tuvo como consecuencia la muerte de miles de portadores de VIH que habían desarrollado SIDA. El protagonista encontrará en esta coyuntura un lugar y una causa.

¿Cómo se despliega la deriva segregacionista? Podemos localizar un entramado ideológico que empuja hacia la segregación, discursos conservadores que rechazan las transformaciones y los modos de existencia que difieren de los ideales y exigencias establecidos hegemónicamente. Lo diferente se presenta como una amenaza ante la cual se promueven discursos y prácticas que robustecen la marginación de quienes no se adaptan. Desde una perspectiva psicoanalítica, encontramos la referencia a Freud donde sitúa la segregación, la separación de unos con otros, a partir de la identificación colectiva a un Ideal del yo (Freud, 1921). Tomando la referencia a la identificación, se puede sostener la distinción entre contagiados y no contagiados, dando lugar a grupos que pueden adquirir una consistencia tal que derive en el odio hacia lo distinto, lo extranjero frente al grupo de pertenencia. 
No obstante, hay que destacar que no se trata solo de una cuestión de identificación. También se encuentra la dimensión del goce, para la cual no hace falta una ideología en particular, lo que Lacan desarrolla considerando el significante de racismo:

no existe ninguna necesidad de esta ideología para que se constituya un racismo, basta un plus-de-gozar que se reconozca como tal. Quienquiera que se interese un poco en lo que puede sobrevenir hará bien en pensar que todas las formas de racismo, en la medida que un plus-de-gozar sirve para soportarlo, están hoy a la orden del día. (Lacan, 1971, p.29)

De este modo, lo estructural del racismo encontrará diversos objetos a partir de los cuales reinstalar el rechazo hacia aquello que representa un goce que se vuelve ajeno: "El racismo, en efecto, cambia sus objetos a medida que las formas sociales se modifican, pero, según la perspectiva de Lacan, siempre yace, en una comunidad humana, el rechazo de un goce inasimilable, resorte de una barbarie posible" (Laurent, 2014, s/p). Ron da cuenta de cómo se puede estar ubicado en el agente o en el objeto de la segregación frente a un modo de gozar distinto. También da cuenta de la posibilidad de que dichas posiciones se transformen, pudiendo encontrar un modo de resistir a la deriva segregacionista.

\section{Las soluciones de Ron}

Si los efectos de la pandemia no son generalizables, las soluciones tampoco. Cada sujeto tomará una posición ante la amenaza o el contagio efectivo. Entre las soluciones que encontró Ron ante el contagio de VIH podemos ubicar en primer lugar que su posición subjetiva no es la de una víctima. En un sentido, sí es una víctima. De la negligencia de las autoridades que en teoría velan por la salud de la población, como también de la segregación de la cual es objeto. Esos son los hechos. Pero en términos subjetivos, no queda coagulado en una posición de víctima. Pienso que se trata de una solución por el riesgo que implica la victimización (Carrasco, 2020). Ron opta por hacer lo necesario para no dejarse morir, para no ser una víctima letal del virus dentro del tiempo estipulado inicialmente. Hay que subrayar que se trata de una decisión del sujeto.

No dejarse morir en el breve tiempo pronosticado por el médico lo lleva a conseguir AZT de modo ilegal. Como no fue indicado por un médico, en una siguiente hospitalización le preguntan cómo lo obtuvo, ante lo cual mantiene silencio. Al percatarse de los efectos tóxicos del fármaco, viaja a México en busca de un mejor tratamiento. En medio del viaje podemos ver por primera vez la desesperación de Ron ante la amenaza de la muerte. Va en busca de un médico que le puede indicar un mejor tratamiento, y lo encuentra. Se producen efectos favorables para su salud. Una vez que vuelve a EEUU, país en que estos medicamentos beneficiosos no son aprobados por la FDA, se las ingenia para poder ingresar. Se disfraza de sacerdote y asegura que es para tratamiento personal. Consigue sortear la dificultad recurriendo a otro semblante. Ya de regreso, se contacta con Rayon y fundan el "Club de compradores de Dallas". Como no pueden vender directamente los fármacos, ofrecen membresías y a través de ellas los compradores pueden acceder a sus dosis.

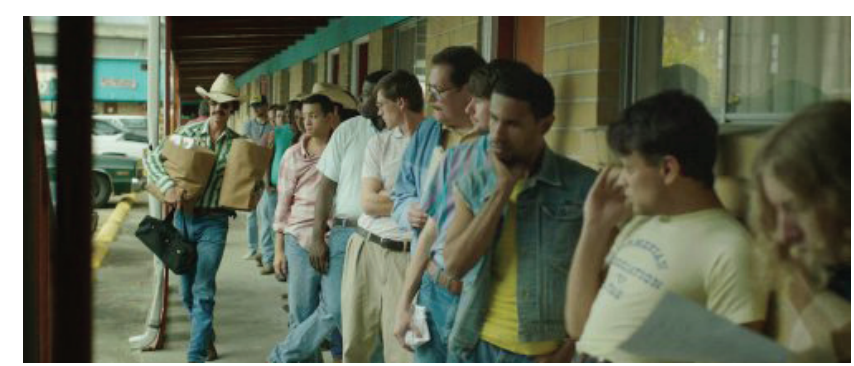

Es notable cómo el protagonista convierte una situación trágica en un negocio que le permite vivir. Con ello, se hace un lugar en un mundo que lo expulsa. Rápidamente va retomando su vida hasta que, tal como expresa en un momento, vuelve a sentirse un ser humano.

Ron continúa sorteando las dificultades, viajando a distintos puntos del mundo para conseguir los medicamentos y mantener el club en funcionamiento. Continúa teniendo problemas legales, al punto de ser auditado por parte de Hacienda. Llegan a confiscar su oficina, a retirar las drogas no aprobadas por la FDA. Decide imponer una demanda contra el gobierno y la FDA.

En este recorrido es crucial la relación que establece con Rayon. Una relación que se transforma. En un primer momento, Rayon encarna algo que para Ron se vuelve insoportable, respondiendo con el rechazo. Luego, al volver con los medicamentos desde México, recurre a ella porque la necesita. Le propone que sean socios. Mediada por la necesidad económica, se produce una apertura incipiente a lo que se le vuelve ajeno. También comienza a frecuentar espacios que antes no hubiera transitado, como bares gays. La relación va mutando hacia una especie de compañerismo, al punto de defenderla cuando es agredida por parte de quien fuera amigo de Ron en el pasado. Lo obliga a saludarla, 
a tratarla con respeto. Hacia el final, se trata de una relación cercana. Cuando Rayon muere, Ron interpela al médico acusándolo de asesino. Afectado por su muerte, decide entregar medicamentos a algunos enfermos sin cobrarles, a pesar de las dificultades económicas que atraviesa el negocio.

No identificarse con el lugar de víctima, crear un lazo con Rayon y crear juntos el club son las soluciones que Ron encuentra y operan como resistencia ante la deriva segregativa. En estas soluciones hay una relación particular con la ley. Por fuera de la ley, para conseguir y distribuir medicamentos no aprobados -e ilegales en otro momento- que le permitieron a él y a varios más acceder a un tratamiento beneficioso. Pero también recurre a la ley, al interpelar a las autoridades por los efectos tóxicos del AZT. La exigencia de poder acceder a otros fármacos le da sentido a su existencia. Luego del juicio obtiene el permiso para continuar un tratamiento que le otorga una mejor expectativa de vida.

\section{Algunas ideas finales}

Dallas Buyers Club nos enseña sobre los fenómenos segregativos que se pueden producir a partir de una pandemia. La segregación aparece como uno de los tratamientos posibles ante lo real que irrumpe con un virus extraño. Por supuesto, un tratamiento que puede llevar a lo peor. Además de los efectos subjetivos de la segregación, Ron nos enseña sobre un modo de resistirse ante la deriva segregativa. Un modo de escapar a la tentativa de quedar petrificado como objeto de desecho de una comunidad. Para ello, renuncia a un semblante de virilidad tradicional y consiente una apertura hacia lo que hasta entonces se le presentaba como radicalmente ajeno. Se trata de soluciones que implican jugar con la ley. Avanza por fuera de la ley, para luego exigir desde su interior.

Poner énfasis en las soluciones conlleva un riesgo. Suele ocurrir que al hacer referencia al modo en que un sujeto aborda lo traumático aparece la tentación de una generalización. Lo mismo con los efectos que ha tenido un determinado acontecimiento. Como si los cuerpos y subjetividades se impactaran del mismo modo ante la irrupción de un real. Como si el recorrido de otros fuese el camino propio. Concebir, por ejemplo, que los contagiados de un virus componen un grupo que comparte marcas y modos de hacer frente a la enfermedad. Pienso que esa respuesta da consistencia a las identificaciones grupales. Con ello, la segregación está a la vuelta de la esquina.

Una ética que promueve la singularidad va a contracorriente de todo empuje hacia la homogeneización. Ninguna identificación grupal alcanza a nombrar lo más propio, es decir, el modo singular de gozar.

La película nos presenta un personaje complejo, que a ratos despierta el rechazo y a momentos la compasión. Esto varía según la posición que va tomando en el transcurso de la película, como también de los ideales e identificaciones del espectador. Me parece que la sensibilidad ante los fenómenos segregativos es un desafío permanente, en tanto la segregación se renueva todo el tiempo bajo diversas formas. Incluso dentro de los grupos segregados que han luchado y conseguido derechos, conquistando un lugar no garantizado en la sociedad. Tanto el rechazo como la identificación nos mantienen en la lógica segregativa.

El asunto se complejiza aún más cuando consideramos que la segregación da cuenta de un rechazo hacia un modo de gozar ajeno que no se presenta solo en un Otro, sino también en uno mismo. La barrera entre un adentro y un afuera se pone en cuestión. Siguiendo a Jacques-Alain Miller (2011), "si el problema tiene aspecto de insoluble, es porque el Otro es Otro dentro de mí mismo. La raíz del racismo, desde esta perspectiva, es el odio al propio goce. No hay otro más que ese. Si el Otro está en mi interior en posición de extimidad, es también mi propio odio" (p.55).

Dar lugar y valor a las soluciones que un sujeto ha encontrado implica tomar distancia de los propios ideales y de los ideales del amo de turno, que vienen a decir cómo deben ser las cosas. Por supuesto, una cosa es declararlo y otra ponerlo en práctica. No estamos libres de promover discursos y prácticas segregativas. En este punto, hay que desconfiar tanto de otros como de uno mismo. Pienso que una salida posible es la experiencia analítica, en tanto permite a un sujeto estar más advertido de sus ideales, prejuicios, ideologías e identificaciones. Más advertido de sus propias tentaciones segregativas, y del goce que allí se pone en juego. ¿Acaso es posible no rechazar a un otro radicalmente ajeno, sin antes aflojar algunas de las propias identificaciones y obtener un saber sobre el propio goce rechazado? 


\section{Referencias}

Brenner, R. (productor) y Vallée, J-M. (director) (2013). Dallas Buyers Club [cinta cinematográfica]. Estados Unidos: Voltage Pictures.

Brodsky, G. (2003). Acción lacaniana. Entrevista a Graciela Brodsky por Silvia Baudini. En Virtualia. Año II. (N8). Recuperado de: http://www.revistavirtualia.com/storage/articulos/pdf/5P7KXBWlL6DV20d1ae7vNSDj12drl1eDwYa2PFrN.pdf

Brodsky, G. (2016). Trauma. ¿Realidad o real? En Bitácora Lacaniana N5. Revista de Psicoanálisis de la Nueva Escuela Lacaniana-NEL. Buenos Aires: Grama Ediciones.

Carrasco, J. (2020). Consideraciones sobre la noción de víctima. Lacan XXI, Revista FAPOL online, vol. 9.

Cosenza, D. (2012). Una ética más allá de la moral. Recuperado de: https://www.youtube.com/watch?v=Onofa8p7xZI\&t=6s

Freud, S. (1921). Psicología de las masas y análisis del yo. En Obras Completas, Volumen 18. Buenos Aires: Amorrortu Editores.

Lacan, J. (1965). La ciencia y la verdad. En Escritos 2. Buenos Aires: Siglo XXI Editores.

Lacan, J. (1971). De un discurso que no fuera del semblante. El Seminario de Jacques Lacan. Libro XVII. Buenos Aires: Paidós.

Laurent, E. (2000). Psicoanálisis y salud mental. Buenos Aires: Editorial Tres Haches.

Laurent, E. (2014). El racismo 2.0. Lacan Quotidien. No 371. Recuperado de: http://www.eol.org.ar/biblioteca/lacancotidiano/ LC-cero-371.pdf

Miller, J-A. (2011). Extimidad. Los Cursos Psicoanalíticos de Jacques-Allain Mller. Buenos Aires: Paidós. 